\title{
Analysis of the Effect of Covid-19 on Chemistry Industry Based on U.S. Stock Market
}

\author{
Xi Chen ${ }^{1 \dagger}$, Shan Zhang ${ }^{2 \dagger}$, Zexin $\mathrm{Nie}^{3 \dagger}$ \\ ${ }^{\text {IS }}$ chool of Informatics, University of Edinburgh, Edinburgh, United Kingdom, x.chen-147@sms.ed.ac.uk \\ ${ }^{2}$ Department of Finance, Shan Dong University of Science and Technology (SDUST), Shan Dong, China, \\ kazhangs@sina.cn \\ ${ }^{3}$ Department of Finance, Zhejiang Gongshang University, Hangzhou, China, 15384033268@pop.zjgsu.edu.cn \\ These authors contributed equally.
}

\begin{abstract}
In 2020, the whole world has encountered the Black Swan incident COVID-19 in economy, medical industry, and chemistry industry. In order to investigate the effects on chemistry industry, we use the Fama-French model to calculate and evaluate the sensitivities of industries before and after the pandemic. Based on our results, the interception factor became significant, and Mkt factor tended to be less sensitive than it was before the pandemic. Besides, SMB was significant both before and after the incident, i.e., investors were optimistic about chemistry industry all the time. In addition, the HML was both higher than zero, which indicated the book value remained high. As for RMW, it was less significant after the pandemic, indicating that the average return has basically no difference comparing to those companies with low profitability. CMA factor was redundant, i.e., the average return on portfolio investment has changed basically nothing. These results provide the basis for the investment decision of chemical industry.
\end{abstract}

Keywords: Fama-French model, COVID-19, Chemistry industry.

\section{INTRODUCTION}

Although the vaccines for COVID-19 are developed, the pandemic still affects the daily life and economy around the world. Almost all global supply sectors ranging from pharmaceuticals to foods are influenced by the COVID-19 pandemics. Meanwhile, COVID-19 pandemic was the main inducement for the sudden stock market crash in 2020, began on $20^{\text {th }}$ February 2020 and ended on $7^{\text {th }}$ April. The crash caused a short-lived bear market, and global market returned back in April, though US market indices return to January 2020 level until November 2020 [1]. US stock markets experienced four breakouts from $9^{\text {th }}$ March 2020 to $18^{\text {th }}$ March [2]. The economic performance is still being affected with the virus spreading until now. On this occasion, investment strategy plays a very important role for both individual and corporate investors to make profits. Capital asset pricing model (CAPM) is widely used to evaluate the relationship between the risk and the expected return of specific portfolios, which is equal to risk-free return adding systemic risk premium. The most important coefficient investor is the positive alpha for CAPM. This model is used throughout the financing institutions from 1970 [3]. The results give the investors the required return or discount rate, which can be utilized to find the value of an asset. Based on CAPM, Fama and French added two coefficient to make the model much more efficient. Afterward, they added two more factors, profitability and investment factors, for further improvement of the model, which known as the Fama-French five-factor model.

Fama and French defined and added two factors, profitability (RMW) and investment (CMA) factors, to the Fama-French (FF) three-factor model to consider much of the variations in average returns related to profitability and investment. The results were based on two interpretations of the zero-intercept hypothesis. Besides, with the statistics of empirical test, FF fivefactor model showed a big improvement relative to the FF three-factor model when applied to portfolios with strong profitability and investment tilts. In addition, the regression details are also indicated for the FF fivefactor model [4]. Panopoulou and Plastira found that there is considerable in-sample forecasting ability of the 
SMB, HML, long-term reversal and momentum factors for the US stock returns. However, for the out-of-sample forecasting ability, only the term spread appears to be a valuable predictor at specific horizons. Otherwise, the research found that there was a link between the Fama French factors and the financial variables based on the analysis of 1-month T-bill and the 3-month T-bill [5]. Leite et al use extra factor through VAR approach to test on Fama-French modeling and make three contributions. They confirm that one-month $\mathrm{T}$-bill rate are proxies HMI and SMB. Moreover, the innovations of those state variables can be estimated for any sequence of variables at the factor vector in the VAR. The above result are not suitable for the five-factor model. State variables can only be described by innovations in CPI and the slope of the yield curve, once there is a relevant correlation among all five variables [6]. Huang exams the ability of FF five-factor model to explain the individual stock returns in China during 1994 to 2016. The results shows that when the explained variable is stock returns rather than portfolio returns, the explanatory power of risk factors drops. He argues that potential influences of market microstructure might cause the model performance varies with sample selection. For example, size and value effects in Shenzhen Stock Exchange stronger than that of Shanghai Exchange Besides, results show China market has strong price reversals, indicating the invalidity of momentum factor [7]. Xu and Zhang intended to find out the effectiveness of three factors explain the Chinese stock returns variation. They found out that some unique features in China affect the three factors greatly. Additionally, those features also influence the explanatory power of the three-factor model. They examined the issue of whether the FF three factors should be based on tradable shares or on all outstanding shares. Moreover, the problem is examined that Fama and French used NYSE-listed firms to determine the breakpoints between small and big firms to avoid the overwhelming influence of the large amount of small Nasdaq firms. They closely used FF model to construct the market size and the value factors based on Chinese stock returns, which focuses on impact of the unique features mentioned above on the three factors greatly and the explanatory power of the three-factor model [8]. Suh conducted time-series tests on the CAPM model and the FF three factor model, which are two models that are among the most widely tested asset pricing models [9]. Nevertheless, CAPM has some shortages in estimating the cost of capital and the FF three factor model is identified to be defective as a tool for empirical research and as an application in the estimation of systematic risk and the cost of equity capital. He conducted some research on the following questions: 1) How stock returns and volatilities are connected to the three risk factors; 2) Whether the CAPM beta gives economically consistent and statistically important estimates for the cost of equity of a firm's inter-temporally and cross-sectionally; 3)To what degree does the FF3 model improves the CAPM beta estimates.

As for the effect of COVID-19, Liu et al use FF five factors model and Carhart four factors model to study the heterogeneous effects of the COVID-19 pandemic outbreak. They find impacts vary in different industries. Stock price of transportation and postal services have declined severely while chemical industries and pharmaceutical manufacturing have the opposite trend which have ascended. Furthermore, they use firm-level driving factors to explain the phenomenon and find that firms with high labor intensity are affected less by pandemic and firms located downstream in the supply chain are more likely to be affected by pandemic [10]. Akhtaruzzaman et al. used FF five-factor models with the empirical data before and during COVID-19 to analyze oil price risk exposure of financial and nonfinancial industries. Besides, they also investigated the negative effect on the economic growth and stock returns around the world during the COVID-19 pandemic. The results indicate that the oil price exposure of financial and non-financial industries remains similar across regions. Meanwhile, the research found that oil-substitute and oil-related industries had less pronounced positive exposure to oil price risk during the COVID-19 period than the non-COVID-19 period [11].

In this paper, we investigate the effect of COVID-19 on the stock return of chemistry industries in US stock market. We use the empirical data before and during the outbreak of the pandemic and analyze the data by regressions for FF five factors model in these two periods separately. Subsequently, we compare all factors respectively to determine which factor was affected by COVID-19, and also illustrate the influencing factors for each factor. These results will provide relative investment suggestions on the chemistry industries in US stock market.

\section{METHOD}

CAPM (Capital Asset Pricing Model) is a single factor model, which explains the stock expect return basing on market risk (systematic risk). It assumes that every investor has same personal preference and dividends are already included in the return on market portfolio. According to CAPM, the expected excess return $E\left(R_{i}\right)$ on an asset is given by:

$$
E\left(R_{i}\right)=R_{f}+\beta_{i}{ }^{M}\left(E\left(R_{m}\right)-R_{f}\right)
$$

where $R_{i}$ indicates return of stock $i, R_{f}$ represents risk free return, $\beta_{i}{ }^{M}$ is the systematic risk of asset $i$ relative to the market portfolio [12].

Instead of using systematic risk as measured only, Fama and French(1993) introduced three-factor Fama- 
French model which is an expanding alternative to CAPM , adding size and value variables to illustrate the excess return. FF three factor model use market factor $\left(R_{m}\right)$, market value factor $(M E)$ and book-to-value factor $(H M L)$ to illustrate the stock return. The FF threefactor model is statistical regression as:

$R_{i}-R_{f}=\alpha_{i}+\beta_{m}\left(R_{m}-R_{f}\right)+\beta_{s} S M B+\beta_{h} H M L+\varepsilon_{i}$ (2)

where $R_{i}$ indicates return of stock $i, R_{f}$ represents risk free return, $\alpha_{i}$ and $\varepsilon_{i}$ are intercept and residual, $R_{m}$ describes market portfolio return, $S M B$ is the return on a portfolio of small firms minus that of large firms and $H M L$ states return of stocks with high versus low simulating portfolio return rate of book-to-value factor, $\beta_{m}, \beta_{s}, \beta_{h}$ shows sensitive coefficient of three factors respectively, $\varepsilon_{i}$ is the residual excess return on portfolio during the period.

The three-factor model was further extended Carhart (1997) into four- factor model, adding price momentum factor to represent the negative tendency of firms' past returns to further returns and that of positive tendency. The four-factor model is statistical regression as:

$R_{i}-R_{f}=\alpha_{i}+\beta_{m}\left(R_{m}-R_{f}\right)+\beta_{S} S M B+\beta_{h} H M L+$ $\beta_{m} \mathrm{MOM}_{+} \varepsilon_{i}(3)$

where price momentum factor is the average return on best return performance minus that of the worst return performance [13].

Fama-French five-factor model add extra two factors basing on three-factor model, which are operating profitability factor(RMW) and investment factor (CMA). The five-factor Fama-French model is:

$R_{i}-R_{f}=\alpha_{i}+\beta_{m}\left(R_{m}-R_{f}\right)+\beta_{s} S M B+\beta_{h} H M L+\beta_{c} C M A$ $+\beta_{r} R M W+\varepsilon_{i}$

where $C M A$ represents the investment premium and $R M W$ indicates the profitability premium, $\beta_{r}, \beta_{c}$ denotes sensitive coefficient of two factors mentioned.

\section{RESULTS}

This paper adopts the chemistry industry of 30 daily portfolios data for US stock market [14], which are analyzed before and during the period of COVID-19 outbreak by FF five-factor model. The sample period is from March 2019 to February 2020 before COVID-19, and from March 2020 to February 2021 during the period, which are analyzed in years. The coefficients of factors are obtained after multiple linear regression, using OLS.

TABLE I. REGRESSIONS FOR FAMA-FRENCH FACTORS FOR CHEMISTRY INDUSTRY BEFORE COVID-19

\begin{tabular}{lccc}
\hline Coefficients & $\begin{array}{c}\text { Standard } \\
\text { error }\end{array}$ & t Stat & P-value \\
\hline
\end{tabular}

$\begin{array}{ccccc}\text { Intercept } & -0.055 & 0.036 & -1.547 & 0.123 \\ \text { Mkt-Rf } & 1.063 & 0.044 & 24.030 & 1.761 \times 10^{-66} \\ \text { SMB } & 0.832 & 0.079 & 10.556 & 9.940 \times 10^{-22} \\ \text { HML } & 0.285 & 0.080 & 3.588 & 0.000402 \\ \text { RMW } & 0.485 & 0.125 & 3.874 & 0.000137 \\ \text { CMA } & 0.077 & 0.158 & 0.488 & 0.626\end{array}$

TABLE II. REGRESSIONS FOR FAMA-FRENCH FACTORS FOR CHEMISTRY INDUSTRY DURING COVID-19

\begin{tabular}{ccccc}
\hline & Coefficients & $\begin{array}{c}\text { Standard } \\
\text { error }\end{array}$ & t Stat & P-value \\
& & & & \\
Intercept & 0.155 & 0.060 & 2.607 & 0.010 \\
Mkt-Rf & 0.940 & 0.029 & 32.135 & $7.742 \times 10^{-90}$ \\
& & & & \\
SMB & 0.806 & 0.069 & 11.654 & $2.914 \times 10^{-25}$ \\
& & & & \\
HML & 0.277 & 0.057 & 4.886 & $1.861 \times 10^{-6}$ \\
RMW & 0.014 & 0.116 & 0.119 & 0.905 \\
CMA & -0.010 & 0.130 & 0.0736 & 0.941 \\
& & & & \\
\hline
\end{tabular}

Table 1 and Table 2 show the statistics for FF five factors before and during COVID-19 pandemic. We compare the data between these two periods, including interception, which t-values become significant during COVID-19 and increasing to 2.61. Then, for Mkt-Rf, SMB and HML, t-values are all obviously significant. RMW is significant before COVID-19 with accepted tvalue and p-value, while the value during COVID-19 is insignificant. The CMA in the whole period remain redundant.

\section{DisCUSSION}

\subsection{Interception}

As shown in Table 1 and Table 2, the value of interception became considerable bigger after the pandemic, from -0.055 to 0.155 , which indicates the interception changes to be significant and has an anomaly after the outbreak. It illustrates that other factors became more sensitive because of the effect of the pandemic. Throughout the pandemic, chemical products have been affected in various aspects ranging from positive to negative. According to Kevin Swift, the chief of American Chemistry Council[15], the impact of COVID-19 and decline of oil prices have led to a sharp decline at $8 \%$ in U.S. GDP in the second quarter, which became more than a demand shock now in comparison 
with a supply shock in the past. Since the chance of U.S. recession increased to $50 \%$ in March, he expected the American economic would shrink by more than $8 \%$, and the U.S. GDP would descend by $17.5 \%$ in the second quarter. The phenomenon indicates a decrease in the demand of the U.S. market would happen, i.e., give rise to lower chemical consumption. As a follow-up, the decline in fuel demand would affect the demand for petroleum additives, which causes lower demand of chemicals (e.g., detergents and other cleaning chemicals using in restaurants and hotels due to huge negative impact on tourism). Besides, the depression in traditional industry, automobile manufacturing in America also influences chemicals through wheel materials (e.g., SBR and BD), which shows a sharp decrease. However, there is a long-term demand of hand sanitizers due to the high probability of long-lasting pandemic. Meanwhile, the demand of medical supplies is stimulated to a surge all over the world lead to boost the chemicals' need.

\subsection{Market}

The coefficients of Mkt- $\mathrm{R}_{\mathrm{f}}$ is above 1 , which declined to below 1 after the pandemic. The change of coefficients means that chemistry industry was sensitive to market before COVID-19 though the sensitivity has decreased after the "Black Swan"incidents.

Chief economist Kevin Swift from American Chemistry Council (ACC) examined the North America chemical industry in a webinar held by ICIS[15]. According to Kevin Swift, the COVID-19 outbreak began as a shock in the supply-side, and has now become a demand-side shock. The ultimate severity of the recession will depend on the depth, prevalence and durability of the impact of the epidemic. Besides, the effect from the pandemic, the sharp decrease of oil price had even worse impact on the America economic. The advent of shale oil and gas has transformed the US from a large importer of crude oil and refined products into a net exporter. Oil and gas production has accounted for much of the growth in the U.S. economy. Though the lower price of oil will cut fuel costs, the quarantine had contributed zero demand from consumers. As a result, the price of crude oil had dropped to an unprofitable level. All sectors of downstream or upstream enterprises of the chemistry industry chain are affected by the combined impact of falling oil prices and the COVID-19 outbreak in different level.

The auto industry, as an important downstream industry for the chemical industry, had suffered a severe downward trend since the drop in car sales and travel will not vanish in a short time. Therefore, the demand of chemicals (e.g., adhesive, antifreeze, catalyst, paint, fiber, and plastic instrument panel) is unlikely to increase back to its original level.

\subsection{SMB}

The coefficient of SMB turns to be considerable significant in both periods, from 0.832 to 0.806 , which shows slightly difference, i.e., presents the pandemic did not obviously influenced the effect of small company's efficiency. The stability indicates that investors were optimistic about the overall development of chemical industry throughout the COVID-19. The investors tend to invest similarly because an upward trend would appear relative to the industry. Additionally, the chemical industry is a traditional industry which market share of it has already steadily occupied. Therefore, it is more steady compared with emerging industry and less huge changes which ensure the confidence of investing. At the same time, many scholars agree that small company's efficiency origins from risk premium that non-systematic risk of investors' expected return produced, which means chemical industry maintains its non-systematic risk all along. Moreover, the explosion of these small firms remained the way investors think about chemical industry. In this case, there are favorable policies of small companies like "small business award" that inspires investor to concern about small companies to reap more profits despite the non-systematic risk.

\subsection{HML}

The book-to-market ratio is the calculated rate between a company's book performance and the value of shares issued. A stock with a high book-to-market value is considered as a highly valuable investment. Even though some parts of the chemistry industry had suffered while some industries are getting their signs of developments, chemistry industry is still worth the wait.

Before the Black Swan incident, the auto industry had already suffered a floundering trend in 2019, which has kept a downward trend after the outbreak of the pandemic. Nevertheless, during the long time of prevention, some new habits have formed and seems to last long in the future, e.g., the use of disinfection products, working from home, shopping online, etc. These brand new changes may lead to a far-reaching implication for the whole chemical supply chain. The chemistry industry may will focus more on PET, the raw material for bottled water; or focus on bygiene products such as hand sanitizers or the isopropyl alcohol (IPA), which is the main ingredient in hand sanitizers.

\subsection{RMW}

The RMW factors turn from significant before the epidemic to insignificant during COVID-19, indicating that the average return on the robust operating profitability portfolios has no significant difference from companies with poor profitability. 
The reason for this should be the supply chains for chemical industries were disrupted by the pandemic. By American Chemistry Council, total US chemical production volume excluding pharmaceuticals fell by $3.6 \%$, and basic chemical production fell $1.3 \%$ in 2020 [15]. Chemical businesses faced a dire situation in April and May 2020, when COVID-19 forced customers to shut their manufacturing lines [18]. The demand of chemical materials from other industries were also reduced due to the pandemic. For example, the demand of composites used in airplanes decreased owing to tourism limitations applied in most of the countries around the world. From the UNWTO travel restrictions report from the beginning of February 2021, 32\% of all destinations worldwide are completely closed for international tourism, and $34 \%$ of worldwide destinations are now partially closed to international tourists [19]. According to these issues, making profits during COVID-19 was harder compared to before.

On the other fact, the sudden short-lived bear market in March 2021 led to the risk-averse of investors. Rather than the chemistry industries, investment preference of investors tend to other portfolios with lower risk and less affected by the pandemic, e.g., multi-line insurances and specialized REITs.[20] This should also result in difficulties for chemistry industry companies on their cash flow.

\section{6. $C M A$}

Finally, for the CMA factors, they remain redundant, and the difference between the t-values before and during the pandemic is very small as well. It suggests that the average return on investment portfolios of chemistry industries affects quite less in this model than other four factors during both these two periods. The intrinsic is that chemistry industry is one of the main traditional industries, i.e., the investment is hard to influence the industry structure. Their profits are mainly based on chemical manufacturing and businesses. Hence, most part of investment are the equipment, maintenance and administration fees of the toxic substances control act [21].

\section{CONCLUSION}

In summary, we investigate the effects of COVID-19 on chemical industry based on the Fama-French fivefactor model. The results indicate that pandemic indeed had a great impact on the market, which especially turn out to be significant on chemical companies. Comparing with various factors, although pandemic stimulate some chemicals in some extent, chemical industry shock deeply ranging from upstream suppliers to downstream customers. Besides, small companies tends to be more willing by investor. On this basis, investors change their focus from traditional chemical industry to specific chemical products or biochemical industry that is positively relative to COVID-19. Further research will focus on the specific chemicals' profitability that are boosted by pandemic. These results offer a guideline to investor for clearer comprehending of the COVID-19 impact on chemical industry.

\section{REFERENCES}

[1] Smith, E. (2020). World stocks outperform the U.S. in bumper November. CNBC. URL on: https://www.cnbc.com/2020/12/01/world-stocksoutperform-the-us-in-bumper-november.html

[2] Zhang, J. (2020). U.S. stock fuses again! 4 times in 10 days. Global Business Quotient. URL on: https://www.gbizq.com/us-stock-market-fusesagain-4-times-in-10-days/

[3] Fama, Eugene, F., French, \& Kenneth, R. (2004). The capital asset pricing model: theory and evidence. Journal of Economic Perspectives.

[4] Fama, E. F., \& French, K. R. (2014). A five-factor asset pricing model. Journal of Financial Economics, 116(1).

[5] Panopoulou, E., \& Plastira, S. (2014). Fama french factors and us stock return predictability. Journal of Asset Management, 15(2), 110-128.

[6] Leite, A. L., Klotzle, M. C., Pinto, A., \& Barbedo, C. S. . (2020). The fama-french's five-factor model relation with interest rates and macro variables. The North American Journal of Economics and Finance, 53.

[7] Tzu-Lun Huang. (2019). Is the Fama and French five-factor model robust in the Chinese stock market?. Asia Pacific Management Review, 24(3), pp. 278-289.

[8] Zhang, J. (2014). The Fama-French three factors in Chinese stock market. China Accounting and Finance Review

[9] D Suh. (2009). The correlations and volatilities of stock returns: the capm beta and the fama-french factors. SSRN Electronic Journal.

[10]Liu, Z., Zhang, T., \& Zhang, G. . (2020). Heterogeneous stock market reactions to covid-19: more hidden mechanisms. SSRN Electronic Journal.

[11] Akhtaruzzaman, M., Boubaker, S. , Chiah, M. , \& Zhong, A. . (2020). Covid19 and oil price risk exposure. SSRN Electronic Journal. 
[12] Bello, Zakri, \& Y. (2008). A statistical comparison of the capm to the fama-french three factor model and the cahart's model. Global Journal of Finance \& Banking Issues.

[13] Bartholdy, J. , \& Peare, P. . (2005). Estimation of expected return: capm vs. fama and french. International Review of Financial Analysis, 14(4), 407-427.

[14]30 industry portfolios [Daily]. Current research returns. URL on: http://mba.tuck.dartmouth.edu/pages/faculty/ken.fr ench/data_library.html

[15] Scott, J. (2020). Chemistry Industry Outlook: Recovery from the COVID-19 Global Recession[EB/OL]American Chemistry Council. URL on: https://www.americanchemistry.com/Media/PressR eleasesTranscripts/ACC-news-releases/ChemicalIndustry-Outlook-Recovery-from-the-COVID-19Global-Recession.html, APR 17,2020.

[16] Bomgardner, M. M. (2020). US chemical industry to return to growth in 2021. c\&en. URL on: https://cen.acs.org/business/economy/US-chemicalindustry-return-growth/98/web/2020/12

[17] Tightened travel restrictions underline current challenges for tourism. (2021). UNWTO. URL on: https://www.unwto.org/news/tightened-travelrestrictions-underline-current-challenges-fortourism

[18] Haydon, D., \& Kumar, N. . (2020). Industries Most and Least Impacted by COVID-19 from a Probability of Default Perspective - September 2020 Update. S\&P Global. URL on: https://www.spglobal.com/marketintelligence/en/ne ws-insights/blog/industries-most-and-leastimpacted-by-covid19-from-a-probability-ofdefault-perspective-september-2020-update

[19]Fees for the Administration of the Toxic Substances Control Act. (2020). EPA. URL on: https://www.epa.gov/tsca-fees/fees-administrationtoxic-substances-control-act 